\title{
Spectroscopic Evaluation of Chalcone Derivatives and their Zinc Metal Complexes: A Combined Experimental and Computational Approach on the Binding of the Complexes with the Serum Albumin
}

\author{
Manos C. Vlasiou ( $\nabla$ vlasiou.m@unic.ac.cy) \\ University of Nicosia https://orcid.org/0000-0002-8356-0868
}

\section{Research Article}

Keywords: Chalcone, Zinc, Spectroscopy, Docking, Molecular dynamics, Complexes, DFT, BSA

Posted Date: December 30th, 2020

DOl: https://doi.org/10.21203/rs.3.rs-136887/v1

License: (9) This work is licensed under a Creative Commons Attribution 4.0 International License. Read Full License 


\section{Abstract}

Three chalcone derivatives $\left(L_{1}, L_{2}, L_{3}\right)$ were synthesized using Claisen-Schmidt condensation reaction. Their molecular structures and spectroscopic properties (IR, UV-vis, ${ }^{1} \mathrm{HNMR}$ ), were calculated at B3LYP level. Electrostatic interactions and HOMO-LUMO properties were calculated using TD-DFT method. Molecular docking was used to compare the HSA (human serum albumin) interactions with the ligands and their $\mathbf{Z n}$ complexes $\left(\mathbf{C}_{1}, \mathbf{C}_{2}, \mathbf{C}_{3}\right)$ which were synthesized by interaction between the ligands and the $\mathrm{Zn}$ (II) ion in a 2:1 M ratio. Elemental analysis, FT-IR, and UV-Vis spectroscopy studies investigated the structure of the synthesized complexes. UV-Vis, molecular docking and molecular dynamics were used to study the interactions of the $\mathrm{Zn}$ complexes with the BSA (bovine serum albumin). The biological activity of the $\mathrm{Zn}$-Chalcone complexes was generally higher than the chalcones when evaluated spectroscopically and theoretically.

\section{Introduction}

Chalcones, are belonging to the flavonoid family, having a medicinal importance because of the CO$\mathrm{CH}=\mathrm{CH}$ - (ketoethylenic group). There are intermediates of flavonoids and they exhibit anti-inflammatory, antifungal, antimicrobial, antioxidant and antitumor activity $[1,2]$. This biological activity is because of the $a, \beta$-unsaturated keto function. Chalcone contains two aromatic rings linked by a three carbon $a, \beta$ unsaturated carbonic system and they are selected because of their low toxicity and possible chemical modification [3,4]. In nature, chalcone (1,3-diphenyl-2-propen-1-one) is one of the open chain flavonoids containing 15-carbon arranged in a C6C3-C6 configuration [5]. The bioactivity of chalcones have been studied and several biological activities have been found such as, antioxidant, cytotoxic, antiviral, tyrosinase inhibitory, antimalarial, antibacterial, and anti-inflammatory [6]. Additionally, the synthesis of Pd (II) and Pt (II) complexes and Co (II), Cu (II), Mn (III) of a chalcone compound has been proposed elsewhere $[7,8]$ and this is because chalcones are effective metal ion chelators and they can easily create metal-coordinated compounds [9]. Chalcones are synthesized by Claisen-Schmidt condensation. This reaction involves cross aldol condensation of appropriate aldehydes and ketones by base catalysed or acid catalysed reactions followed by dehydration [10].

It is known that Zinc-containing compounds play a key role in carbonic anhydrases, peptidases, proteases, and deaminases [11]. Interestingly, the coordination chemistry of zinc in proteins and peptides involves $\mathrm{N}, \mathrm{O}$, and $\mathrm{S}$ donors of the side chains of histidine, glutamate/aspartate, and/or cysteine with any permutation of these ligands and with the number of protein ligands ranging from three to six [12]. On the other hand, $\mathrm{Zn}$ plays a vital role in a variety of biological processes but, excessive exposure of $\mathrm{Zn}^{2+}$ to human beings can cause toxicity, inducing a series of overt poisoning symptoms and neurodegenerative disorders [13]. 
HSA is responsible to maintaining stable osmotic pressure and to carrying endogenous or exogenous compounds. Additionally, most lipophilic drugs are substrates of HSA and are transferred to target tissues via the bloodstream. The chemical structure of HSA includes three homologous $a$-helical domains (I, II and III), each of which possesses two subdomains (A and B) [14]. Various binding and denaturation studies have shown to be a rapid and effective tool for the characterization of albumin binding sites and their enantioselectivity, and for the study of the changes in the binding properties of the protein caused by interaction between different ligands [15-18].

The last years more and more scientists are using computational chemistry and theoretical tools to evaluate their molecular structures [19-21]. Moreover, some researchers are using computational tools to evaluate the biological activity of the molecules of interest [22-26]. This is because of the quick results that the computational tool is giving to the researcher, and the added scientific value to the findings. All that, at minimum cost and resources. As the technological improvements are running fast, more and more theoretical tools are going to save time to the researcher and give a different perspective, using the predictive character of the computerized models.

Herein, we propose the synthesis of some chalcone analogues, and their complexation with Zn (II) metal ions. In total, 6 molecules were prepared and evaluated spectroscopically, both in situ and theoretically. More specifically, we used TD-DFT studies [26-31], to evaluate our chalcone derivatives in terms of structure and activity, molecular docking [32-35], to evaluate their interaction with human serum albumin (HSA) and spectroscopy to evaluate their binding interactions with bovine serum albumin (BSA). The biological activity of the chalcone derivatives, was compared with the biological activity of their counter Zn complexes.

\section{Experimental}

\subsection{Materials}

2-nitrobenzaldehyde, 2-(methylamino) benzaldehyde, 2-hydroxy-5-methylphenyl ethanone, 1-(2-hydroxy-5methylphenyl) ethanone, 4-hydroxy-3-methoxyphenyl ethanone, were purchased from Merck. Solvents were used without any further purification. Other reagents were of analytical grade. BSA (bovine serum albumin) (purity $\geq 98 \%$ ) was purchased from Merck.

\subsection{Instruments}

All the chalcone analogues and their zinc complexes were characterized by ${ }^{1} \mathrm{HNMR}$, recorded on Bruker $300 \mathrm{MHz}$ spectrometer using DMSO-d6 as solvent and TMS as an internal standard. The chemical shifts were expressed in $\delta \mathrm{ppm}$. The absorption spectrum of all the reaction mixtures was then taken in a range of 200-400 nm in a JASCO (Tokyo, Japan) UV-visible spectrophotometer using a $1 \mathrm{~cm}$ path length quartz cuvette. 
In a round bottom flask $(100 \mathrm{ml})$, to a methanolic solution $(20 \mathrm{ml})$ of 2-hydroxy-5-methylphenyl ethanone $(0.003 \mathrm{~mol})$ a $40 \%$ aqueous $\mathrm{NaOH}$ solution $(15 \mathrm{~mL})$ was gradually added. 2-nitrobenzaldehyde $(0.003$ $\mathrm{mol}$ ) was added and the reaction took place for $20 \mathrm{~h}$ at $25^{\circ} \mathrm{C}$. Any precipitate formed was removed by filtration and the filtrate was acidified with dilute $\mathrm{HCl}$ and then extracted with chloroform. The concentrate of the chloroform was chromatographed over silica gel to obtain the desired product. The compound then crystallized from chloroform-petroleum ether (50:50). Olive green solid, M.P: $55-57^{\circ} \mathrm{C} ;{ }^{1} \mathrm{H} \mathrm{NMR}(300 \mathrm{MHz}$, DMSO-d6): $\delta 2.36\left(\mathrm{~s},-\mathrm{CH}_{3}\right), 5.37(\mathrm{~s},-\mathrm{OH}), 7.04(\mathrm{~m},-\mathrm{CH}$ aromatic), $7.36(\mathrm{~m},-\mathrm{CH}$ aromatic), $7.44(\mathrm{~m},-\mathrm{CH}$ aromatic), $7.65(\mathrm{~m},-\mathrm{H}), 7.89(\mathrm{~m},-\mathrm{CH}), 8.23(\mathrm{~m},-\mathrm{CH}), 8.64(\mathrm{~m} .-\mathrm{H})$ ppm.

\subsubsection{Synthesis of (E)-3-(4-dimethylamino) phenyl)-1-(2-hydroxy-5-methylphenyl) prop-2-en-1-one}

In a round bottom flask $(100 \mathrm{ml})$, to a methanolic solution $(20 \mathrm{ml})$ of 2-hydroxy-5-methylphenyl ethanone $(0.003 \mathrm{~mol})$ a $40 \%$ aqueous $\mathrm{NaOH}$ solution $(15 \mathrm{~mL})$ was gradually added. 4-dimethylamino benzaldehyde $(0.003 \mathrm{~mol})$ was added and the reaction took place for $20 \mathrm{~h}$ at $25^{\circ} \mathrm{C}$. Any precipitate formed was removed by filtration and the filtrate was acidified with dilute $\mathrm{HCl}$ and then extracted with chloroform. Orange solid, M. P: $54-55^{\circ} \mathrm{C} ;{ }^{1} \mathrm{H}$ NMR (300 MHz, DMSO-d6): $\delta 2.34\left(\mathrm{~s},-\mathrm{CH}_{3}\right), 3.06\left(\mathrm{~s},-\mathrm{CH}_{3}\right), 5.35(\mathrm{~s},-\mathrm{OH}), 7.02(\mathrm{~m},-\mathrm{CH}$ aromatic), 7.34 (m, $-\mathrm{CH}$ aromatic), $8.33(\mathrm{~d},-\mathrm{H})$ ppm.

\subsubsection{Synthesis of (E)-1-(2-hydroxy-5methoxyphenyl)-3-(2-nitrophenyl) prop-2-en-1-one}

In a round bottom flask $(100 \mathrm{ml})$, to an ethanolic solution $(20 \mathrm{ml})$ of 1-(4-hydroxy-3methoxyphenyl) ethanone $0.003 \mathrm{~mol}$ ) a $40 \%$ aqueous $\mathrm{NaOH}$ solution $(20 \mathrm{~mL})$ was gradually added. 2-nitrobenzaldehyde $(0.003 \mathrm{~mol})$ was added and the reaction took place for $24 \mathrm{~h}$ at $25^{\circ} \mathrm{C}$. Any precipitate formed was removed by filtration and the filtrate was acidified with dilute $\mathrm{HCl}$. Yellow-green solid, M. P: $57-59^{\circ} \mathrm{C} ;{ }^{1} \mathrm{H}$ NMR (300 MHz, DMSO-d6): $\delta 3.84$ (s, -CH3), $5.33(\mathrm{~s},-\mathrm{OH}), 7.10$ (m, -CH aromatic), 7.27 (m, - $\mathrm{CH}$ aromatic), 7.79 ( $\mathrm{m},-$ $\mathrm{CH}$ aromatic), 7.89 (m, $-\mathrm{CH}$ aromatic), 8.21 ( $\mathrm{m},-\mathrm{CH}$ aromatic), $8.60(\mathrm{~d},-\mathrm{H})$.

\subsection{Synthesis of Zinc (II) Complexes}

Zn (II) complexes with ligands $L_{7}-L_{3}$

An ethanolic solution $(30 \mathrm{ml})$ of $\mathrm{Zn}(\mathrm{II})$ chloride $(0.01 \mathrm{~mol})$ was added to a refluxing solution of appropriate chalcone analogue $L_{1}-L_{3}(0.02 \mathrm{~mol})$ in ethanol $(30 \mathrm{ml})$. The reaction mixture was refluxed for $6 \mathrm{~h}$. The coloured complexes were obtained, filtered off, washed with ethanol and dried under vacuum. Elemental Analysis: L1: C, 54.84; H, 3.45; Cl, 10.12; N, 4.00; O, 18.26; Zn, 9.33. L2: C, 62.04; H, 5.21; Cl, 10.17; N, 4.02; O, 9.18; Zn, 9.38. L3: C, 52.45; H, 3.30; Cl, 9.68; N, 3.82; O, 21.83; Zn, 8.92.

\subsection{Theoretical Studies}

2.5.1 Optimization and vibration frequency calculations were made at B3LYP level with ORCA version 4.0.1 program. B3LYP is a hybrid density functional theory method. Among the ever-increasing number of 
DFT methods, the hybrid functional B3LYP, as a good compromise between computational cost, coverage, and accuracy of results [36]. It has become a standard method used to study organic chemistry in the gas phase. UV-vis spectrums at the same level calculated by time-dependent density functional theory (TD-DFT) method. ORCA input files were created by AVOGADRO version 1.2.0 software. HOMO energy ( $\left.\mathrm{E}_{\mathrm{HOMO}}\right)$ and LUMO energy ( $\left.\mathrm{E}_{\mathrm{LUMO}}\right)$ were taken from the output file. Chalcone analogues and their zinc complexes were docked against human serum albumin. Molecular docking studies were carried out by using iGEMDOCK 2.1 software [11]. The HSA coded crystal structure was selected from the Protein Data Bank (www.rcsb.org). The population size was $=200$, generations $=70$, number of solutions $=3$.

\subsection{Effect of the ligand and the complex on the absorption spectrum of BSA}

The effect of the ligands and their corresponding complexes, on the absorption spectrum of BSA, was studied using UV-visible spectrophotometry. Briefly, BSA $(5 \mu \mathrm{M})$ were incubated in the absence and presence of $2-9 \mu \mathrm{M}$ of $\mathrm{L}_{1}, \mathrm{~L}_{2}, \mathrm{~L}_{3}, \mathrm{C}_{1}, \mathrm{C}_{2}$ and $\mathrm{C}_{3}$ for $30 \mathrm{~min}$ at $\mathrm{RT}$.

\section{Results And Discussion}

\subsection{Synthesis of Chalcone Derivatives and their Zinc Complexes}

Chalcone derivatives were synthesized based on Claisen-Schmidt condensation reaction. Acetophenones analogues reacted in (1:1) ratio with benzaldehydes analogues in methanolic solutions resulting the chalcone derivatives $\left(L_{1}, L_{2}\right.$ and $\left.L_{3}\right)$. The synthetic routes and conditions are depicted in Fig. 1. Reactions took place at room temperature resulting colourful precipitates after $20 \mathrm{~h}$ mixing. Any precipitate formed was removed by filtration before acidification. The formation of carbanion or enolate ions is considered to be the first stage of the condensation reaction. Aromatic ketones having a hydrogen if treated with alkaline solutions (in this case $\mathrm{NaOH}$ ), the hydroxide ion from the base will attack hydrogen $a$ from the ketone so that a carbanion is formed which can be stabilized by resonance and release the $\mathrm{H}_{2} \mathrm{O}$ molecule. Followed by the second stage which is a nucleophilic addition reaction. Here, the enolate or carbanion ion formed at stage one acts as a nucleophile that attacks the carbonyl group of benzaldehyde. An alkoxide ion is formed which has an excess of electron charge in the 0 atom. Next, is the formation of an aldol. Aldol is a compound formed from aldehydes and ketones where aldol takes protons from solvent molecules, $\mathrm{H}_{2} \mathrm{O}$. Alkoxide ions take hydrogen protons from $\mathrm{H}_{2} \mathrm{O}$ molecules to form $\beta$ hydroxyketone (aldol). Then the hydroxide ion from $\mathrm{H}_{2} \mathrm{O}$ binds to the sodium ion and returns to form a $\mathrm{NaOH}$ base catalyst. Finally, the dehydration reaction of the aldol compound takes place in ClaisenSchmidt reaction. Dehydration reaction is a reaction of the release of water molecules. Carbonyl $\beta-$ hydroxy like aldol is easily dehydrated, because the double bonds in the compound conjugate with the carbonyl group. The disappearance of the chemical shift at $2.5 \mathrm{ppm}$ attributed to $-\mathrm{CH}_{3}$ hydrogens of acetophenone, it is a good evidence of the resulted chalcone derivatives. Moreover, the increase of the melting points from $47^{\circ} \mathrm{C}$ to $57^{\circ} \mathrm{C}$ is another indicator of the successful synthesis. 
Zn (II) complexes $\left(\mathbf{C}_{1}, \mathbf{C}_{2}\right.$ and $\left.\mathbf{C}_{3}\right)$ resulted after mixing ethanolic chalcone derivative solution $\left(L_{1}, L_{2}\right.$ and $\mathrm{L}_{3}$ ) with $\mathrm{ZnCl}_{2}$ at (1:2) ratio, using reflux for $6 \mathrm{~h}$. Coloured complexes obtained after filtration. The three complexes are soluble to DMSO and DMF. Elemental analyser indicated that the complexes have 1:2 metal to ligands stoichiometry of the types $\left[\mathrm{ZnL}_{2}(\mathrm{Cl})_{2}\right]$, whereas $\mathrm{L}$ are the chalcone derivatives resulted after the condensation of the correct acetophenone analogue with the correct benzaldehyde analogue. In addition, low molar conductance values indicate that the complexes are not electrolytes.

\subsection{Theoretical Studies on Chalcone Derivatives}

\subsubsection{Molecular Geometry}

The ground state optimization structures of the synthesized chalcone molecules were obtained in the aqueous phase at B3LYP def2-TZVP Grid5 level and are given in Fig. 2.

The geometrical parameters have been procured from optimized molecular structure and summarized in Table 1, giving the main theoretically calculated bond lengths and bond angles of the molecules.

Table 1 Selected bond lengths $(\AA)$ and bond angles $\left({ }^{\circ}\right)$ of the synthesized chalcones.

\begin{tabular}{|c|c|c|c|c|}
\hline L1 & Atoms & Angle & Atoms & Length \\
\hline & C5-C1-O1 & 119.2789 & H4-C8 & 1.08865 \\
\hline & C2-C1-C5 & 118.1423 & C8-C9 & 1.40054 \\
\hline & C1-C7-H1 & 118.5631 & H13-O2 & 0.972961 \\
\hline & C14-C15-N & 122.4757 & C10-O2 & 1.36579 \\
\hline & H10-C16-H12 & 107.4257 & $\mathrm{O} 4-\mathrm{N}$ & 1.23645 \\
\hline & C10-O2-H13 & 109.1858 & $\mathrm{~N}-\mathrm{C} 15$ & 1.47324 \\
\hline & O3-N-O4 & 123.7386 & & \\
\hline & C15-N-O4 & 119.113 & & \\
\hline \multirow[t]{8}{*}{ L2 } & C2-C1-C6 & 120.0083 & H15-C17 & 1.11298 \\
\hline & C1-C2-H1 & 120.0048 & C17-N & 1.47004 \\
\hline & C5-C4-O2 & 120.0014 & C12-C11 & 1.3949 \\
\hline & C12-C13-N & 119.9951 & C7-O1 & 1.20804 \\
\hline & H10-C16-H12 & 109.4628 & H13-O2 & 0.97205 \\
\hline & C4-O2-H13 & 108.0009 & & \\
\hline & C17-N-C18 & 119.9963 & & \\
\hline & N-C17-H15 & 109.4457 & & \\
\hline \multirow[t]{9}{*}{ L3 } & C2-C1-C6 & 119.9986 & H13-C16 & 1.11302 \\
\hline & $\mathrm{C} 2-\mathrm{C} 1-\mathrm{O} 3$ & 120.0016 & C16-O3 & 1.40206 \\
\hline & C3-C2-H1 & 120.033 & C13-C14 & 1.39477 \\
\hline & C14-C15-N & 119.9599 & O5-N & 1.31001 \\
\hline & $\mathrm{C} 4-\mathrm{O} 2-\mathrm{H} 10$ & 107.9991 & C15-N & 1.24809 \\
\hline & C1-O3-C16 & 110.8014 & H10-O2 & 0.971976 \\
\hline & H12-C16-H13 & 109.5253 & & \\
\hline & O3-C16-H1 1 & 109.4976 & & \\
\hline & C15-N-O4 & 120.004 & & \\
\hline
\end{tabular}




\subsubsection{Spectroscopy}

The spectroscopic UV-vis spectrum of the three ligand molecules, and their electronic transitions can be computerized and analyzed by time-depended density functional theory or TD-DFT. Additional information in the molecular structure prediction can be taken by electronic spectroscopy. In Fig. 3 we can see the calculated UV-vis spectrum of the molecules taken in the aqueous phase using B3LYP def2-TZVP Grid5 level algorithm.

As seen in Fig. 3, for $L_{1}$ and $L_{3}$ are observed similar spectrums giving two bands for $\boldsymbol{\pi}$ à $\boldsymbol{\pi}^{\star}$ and $\boldsymbol{n a ̀} \boldsymbol{\pi}^{*}$ transitions respectively. Most absorption spectroscopy of organic compounds is based on transitions of $\mathrm{n}$ or $\pi$ electrons to the $\pi^{\star}$ excited state. This is because the absorption peaks for these transitions fall in an experimentally convenient region of the spectrum $(200-700 \mathrm{~nm})$. These transitions need an unsaturated group in the molecule to provide the $\pi$ electrons. For $L_{2}$ molecule only one transition is observed the $\pi \boldsymbol{n a}^{*}$. The similarity of the bands shapes and close wavelengths show that the structures of the studied molecules are quite similar as they are belonging to the same family of the chalcones. ${ }^{1}$ HNMR spectrum calculated data also suggest the similarity of the structures.

For structural characterization ${ }^{1} \mathrm{HNMR}$ spectra of chalcone molecules were calculated and peaks were attributed to the correct chemical groups. Chemical shifts were given according to the TMS reference and calculated from $\delta=\Sigma_{\mathrm{TMS}}-\Sigma_{\text {relation, }}$ whereas $\Sigma_{\mathrm{TMS}}$ corresponds to the shielding of proton to the TMS and $\Sigma$, the shielding of proton in the sample. The ${ }^{1} \mathrm{HNMR}$ spectrum calculated at B3LYP DEF2-TZVPP DEF2 level in aqueous phase and are given in Fig. 4.

Chemical shifts of ${ }^{1} \mathrm{HNMR}$, are given in Table 2.

Table 2. ${ }^{1}$ HNMR chemical shifts of chalcone molecules calculated at aqueous phase. 


\begin{tabular}{|c|c|c|c|c|c|}
\hline \multicolumn{2}{|l|}{ L1 } & \multicolumn{2}{|l|}{ L2 } & \multicolumn{2}{|l|}{ L3 } \\
\hline Group & Shift (ppm) & Group & Shift (ppm) & Group & Shift (ppm) \\
\hline $\mathrm{OH}$ & 5.35 & $\mathrm{OH}$ & 5.35 & $\mathrm{OH}$ & 5.35 \\
\hline $\mathrm{CH}$ & 7.02 & $\mathrm{CH}$ & 7.02 & $\mathrm{CH}$ & 7.1 \\
\hline $\mathrm{CH}$ & 8.21 & $\mathrm{CH}$ & 6.71 & $\mathrm{CH}$ & 7.33 \\
\hline $\mathrm{CH}$ & 7.43 & $\mathrm{CH}$ & 7.43 & $\mathrm{CH}$ & 8.21 \\
\hline $\mathrm{CH}$ & 8 & $\mathrm{CH}$ & 7.2 & $\mathrm{CH}$ & 7.27 \\
\hline $\mathrm{CH}$ & 7.34 & $\mathrm{CH}$ & 7.34 & $\mathrm{CH}$ & 8 \\
\hline $\mathrm{CH}$ & 7.89 & $\mathrm{CH}$ & 7.15 & $\mathrm{CH}$ & 7.89 \\
\hline $\mathrm{CH}$ & 7.79 & $\mathrm{CH}$ & 6.74 & $\mathrm{CH}$ & 7.89 \\
\hline $\mathrm{CH}_{3}$ & 2.34 & $\mathrm{CH}_{3}$ & 3.06 & $\mathrm{CH}_{3}$ & 3.83 \\
\hline $\mathrm{H}$ & 8.02 & $\mathrm{CH}_{3}$ & 3.06 & $\mathrm{H}$ & 8.62 \\
\hline \multirow[t]{3}{*}{$\mathrm{H}$} & 7.66 & $\mathrm{CH}_{3}$ & 2.34 & $\mathrm{H}$ & 7.66 \\
\hline & & $\mathbf{H}$ & 8.33 & & \\
\hline & & $\mathbf{H}$ & 7.42 & & \\
\hline
\end{tabular}

As can be seen in Fig. 4, the spectra are similar for molecules $L_{1}, L_{3}$ same as the UV-vis spectra. The only difference is the shift of the first chemical shift from 3.83 to 2.34 ppm due to the presence of the extra methyl group on $L_{3}$. The presence of the $3.06 \mathrm{ppm}$ chemical shift that it is characteristic for the $L_{2}$ and corresponds to the $-\mathrm{CH}_{3}$ group of the molecule, dominates the anomeric region. Because they are attached to carbon atoms with low s-character hybridization $\left(s p^{3}\right)$ the found in a low ppm chemical shift. The aromatic region of the spectra of the three chalcone derivatives are quite similar. As can be seen from Table 2. the - $\mathrm{OH}$ group is present at three molecules as well, at the same chemical shift $5.35 \mathrm{ppm}$. The hydrogens of the phenol group of the chalcones can be found at 8.02 and 7.66 ppm for $L_{1}, 8.33$ and 7.42 ppm for $L_{2}$, and 8.62 and 7.66 ppm for $L_{3}$.

An additional way to verify the structures of the chalcone derivatives, is the vibrational spectrum. It has been calculated by BP86 DEF2-SVP FREQ algorithm. The high intensity peaks with the harmonic vibration frequencies are given in Fig. 5.

The characteristic high frequency peak at $3500 \mathrm{~cm}^{-1}$, of $\mathrm{s}(\mathrm{O}-\mathrm{H})$ is common for the three analogues, while the peak at $1200 \mathrm{~cm}^{-1}$ for $L_{1}$, indicating the $s(\mathrm{~N}-\mathrm{H})$ vibration. The methoxy group of $\mathrm{L}_{3}$, is responsible for the $t(\mathrm{H}-\mathrm{O}-\mathrm{C}-\mathrm{C})$ vibration at $800 \mathrm{~cm}^{-1}$ which is absent for $\mathrm{L}_{1}$ and $\mathrm{L}_{2}$. The $1700 \mathrm{~cm}-1$ peak is responsible for the $s(\mathrm{~N}-\mathrm{C})$ of the molecules, while the $1500 \mathrm{~cm}^{-1}$ peak is responsible for $\mathrm{s}(\mathrm{N}-\mathrm{O})$ that is why it is absent from $L_{2}$.

\subsubsection{Molecular Orbital Studies}

The molecular orbital studies revealed the energy gap between the highest molecular orbital (HOMO) and the lowest molecular orbital (LUMO). The value of the energy difference between HOMO and LUMO as well as the highest occupied molecular orbital (EHOMO) and lowest unoccupied molecular orbital (ELUMO) energies plays a very important role in stability and reactivity of molecules. The EHOMO 
energies of molecules show the molecule's ability to give electrons. On the other hand, ELUMO characterizes the ability of the compound to accept electrons. Thus, the one is nucleophile and the other electrophile. Molecules with small energy gaps are considering to have a higher chemical reactivity and softer structures, while molecules having larger energy gaps are considering to be more stable and chemically harder. The computed values of the three chalcone derivatives can be found in Fig. 6 .

It seems that $\mathrm{L}_{3}$, has the highest reactivity $(\Delta \mathrm{E}=0.38 \mathrm{eV})$ followed by $\mathrm{L}_{1}(\Delta \mathrm{E}=2.24 \mathrm{eV})$ and $\mathrm{L}_{2}(\Delta \mathrm{E}=2.34$ eV). In Table 3. we can see all the calculated energy features of the three molecules including, enthalpy, entropy and Gibbs energy. Any process in which the number of particles in the system increases consequently results in an increase in disorder. This is why we can observe an increase in the entropy of the molecules.

Table 3. Calculated energy values of the molecules.

\begin{tabular}{|c|c|c|c|}
\hline Molecule & L1 & L2 & L3 \\
\hline Potential Energy (Kcal/mol) & -2.015 & -1.871 & -2.175 \\
\hline Kinetic Energy (Kcal/mol) & 1.003 & 9.317 & 1.089 \\
\hline Magnitute (a.u) & 2.202 & 3.991 & 2.326 \\
\hline Zero Point Energy (Kcal/mol) & 157.90 & 215.90 & 237.07 \\
\hline Total Thermal Energy (Kcal/mol) & -1.013 & -9.385 & -1.085 \\
\hline Total Enthalpy (Kcal/mol) & -1.013 & -9.385 & -1.085 \\
\hline Final Entropy (Kcal/mol) & 37.09 & 33.74 & 33.11 \\
\hline Gibbs Free Energy (Kcal/mol) & -1.013 & -9.386 & -1.085 \\
\hline $\mathrm{E}_{\text {Lumo }}(\mathrm{eV})$ & -1.817 & 0.58 & -4.259 \\
\hline $\mathrm{E}_{\mathrm{Homo}}(\mathrm{eV})$ & -4.057 & -1.757 & -4.646 \\
\hline$\Delta_{\mathrm{E}}(\mathrm{eV})$ & 2.24 & 2.34 & 0.38 \\
\hline
\end{tabular}

The individual charge on each atom on the molecule, it is another factor used to characterised molecular structures and it is presented by the Mulliken population study. The Mulliken atomic charges have been calculated by DFT method and presented in Table 4.

Table 4. Calculated Mulliken atomic structures of the synthesised structures. 


\begin{tabular}{|c|c|c|c|c|c|c|c|c|c|c|c|c|c|}
\hline & & L1 & & L2 & & L3 & & & L1 & & L2 & & L3 \\
\hline 0 & C & 0.063637 & C & 0.129145 & C & 0.196881 & 21 & $\mathrm{H}$ & 0.016168 & $\mathrm{H}$ & -0.12029 & $\mathrm{O}$ & -0.45753 \\
\hline 1 & C & -0.01498 & C & -0.06418 & C & -0.16668 & 22 & $\mathrm{H}$ & 0.055123 & $\mathrm{H}$ & -0.66633 & $\mathrm{H}$ & 0.121061 \\
\hline 2 & C & 0.006626 & $\mathrm{C}$ & -2.15955 & C & -0.20199 & 23 & $\mathrm{H}$ & -0.0143 & $\mathrm{H}$ & 0.131908 & $\mathrm{H}$ & 0.126387 \\
\hline 3 & $\mathrm{C}$ & 0.005301 & $\mathrm{C}$ & 0.145811 & $\mathrm{C}$ & 0.216942 & 24 & $\mathrm{H}$ & -0.01752 & $\mathrm{H}$ & 0.111987 & $\mathrm{H}$ & 0.174554 \\
\hline 4 & $\mathrm{C}$ & -0.01552 & $\mathrm{C}$ & 0.086392 & $\mathrm{C}$ & -0.01596 & 25 & $\mathrm{H}$ & -0.02783 & $\mathrm{H}$ & 0.120226 & $\mathrm{H}$ & -0.809 \\
\hline 5 & $\mathrm{O}$ & -0.18649 & $\mathrm{O}$ & -0.37377 & $\mathrm{C}$ & 0.011232 & 26 & $\mathrm{H}$ & 0.007255 & $\mathrm{H}$ & 0.092538 & $\mathrm{H}$ & -0.40756 \\
\hline 6 & $\mathrm{C}$ & -0.03756 & $\mathrm{C}$ & -0.31097 & $\mathrm{C}$ & 0.186225 & 27 & $\mathrm{H}$ & 0.011455 & $\mathrm{H}$ & 0.086498 & $\mathrm{H}$ & 0.08526 \\
\hline 7 & C & -0.03731 & $\mathrm{C}$ & 0.221231 & $\mathrm{C}$ & -0.19805 & 28 & $\mathrm{H}$ & 0.011051 & $\mathrm{H}$ & 0.0899 & $\mathrm{H}$ & 0.108883 \\
\hline 8 & $\mathrm{C}$ & -0.01681 & $\mathrm{C}$ & -0.14285 & $\mathrm{C}$ & 0.219312 & 29 & $\mathrm{H}$ & 0.018982 & $\mathrm{H}$ & 0.08746 & $\mathrm{H}$ & 0.124392 \\
\hline 9 & C & -0.07558 & $\mathrm{C}$ & -0.21923 & $\mathrm{C}$ & -0.06535 & 30 & $\mathrm{H}$ & 0.023503 & $\mathrm{H}$ & 0.116634 & $\mathrm{H}$ & 0.152466 \\
\hline 10 & $\mathrm{C}$ & 0.139354 & $\mathrm{C}$ & 0.108108 & $\mathrm{C}$ & -0.1448 & 31 & $\mathrm{H}$ & 0.048161 & $\mathrm{H}$ & 0.116973 & $\mathrm{H}$ & 0.341468 \\
\hline 11 & C & -0.02794 & $\mathrm{C}$ & -0.26177 & $\mathrm{C}$ & -0.15484 & 32 & $\mathrm{H}$ & 0.034461 & $\mathrm{H}$ & 0.116384 & $\mathrm{H}$ & 0.134882 \\
\hline 12 & $\mathrm{C}$ & 0.039388 & $\mathrm{C}$ & -0.11634 & $\mathrm{C}$ & -0.05795 & 33 & $\mathrm{H}$ & 0.185554 & $\mathrm{H}$ & 1.869932 & $\mathrm{H}$ & 0.100239 \\
\hline 13 & C & 0.010727 & $\mathrm{C}$ & -0.15529 & $\mathrm{C}$ & -0.17958 & 34 & & & $\mathrm{H}$ & 0.176557 & $\mathrm{H}$ & 0.13827 \\
\hline 14 & C & -0.03116 & $\mathrm{C}$ & -0.17493 & $\mathrm{C}$ & 0.081493 & 35 & & & $\mathrm{H}$ & 0.078148 & & \\
\hline 15 & $\mathrm{C}$ & 0.178551 & $\mathrm{C}$ & 0.023324 & $\mathrm{O}$ & -0.40831 & 36 & & & $\mathrm{H}$ & 0.219539 & & \\
\hline 16 & $\mathrm{C}$ & 0.037741 & $\mathrm{~N}$ & -0.11198 & $\mathrm{O}$ & -0.38967 & 37 & & & $\mathrm{H}$ & 0.141291 & & \\
\hline 17 & $\mathrm{O}$ & -0.16188 & $\mathrm{C}$ & -0.3699 & $\mathrm{O}$ & -0.26285 & 38 & & & $\mathrm{H}$ & 0.111857 & & \\
\hline 18 & $\mathrm{~N}$ & 0.184202 & $\mathrm{O}$ & 0.922754 & $\mathrm{C}$ & -0.17764 & 39 & & & $\mathrm{H}$ & 0.125495 & & \\
\hline 19 & $\mathrm{O}$ & -0.21708 & $\mathrm{C}$ & 0.07014 & $\mathrm{~N}$ & 0.220938 & & & & & & & \\
\hline 20 & $\mathrm{O}$ & -0.19531 & $\mathrm{C}$ & -0.25285 & $\mathrm{O}$ & 1.356872 & & & & & & & \\
\hline
\end{tabular}

The 020 atom has the highest negative charge for $L_{1}$, while for $L_{2}$ the highest negative charge belongs to $\mathrm{C} 2$ atom. For $\mathrm{L}_{3}$ the highest negative charge is that of $\mathrm{C} 2$ atom as well. On the other hand, N18 and H33 atoms are having the highest electropositive charge for $\mathrm{L}_{1}$, and $\mathrm{C} 7$ and $\mathrm{H} 33$ atoms the highest electropositive charge for $\mathrm{L}_{2}$. Finally, for $\mathrm{L}_{3}, \mathrm{C} 3, \mathrm{~N} 19$ and H31 are the most electropositive atoms. The negative charges are due to the electron withdrawing groups that the atoms are attached with and the positive charges are because of the negative charges of the adjacent groups.

\subsection{Biological Evaluation of Chalcone Derivatives and their Zinc Complexes}

\subsubsection{Molecular Docking}

The examination of the biological activity of the three ligand molecules $\left(\mathrm{L}_{1}, \mathrm{~L}_{2}, \mathrm{~L}_{3}\right)$ and their corresponding complexes $\left(\mathbf{C}_{1}, \mathbf{C}_{2}, \mathbf{C}_{3}\right)$, calculated theoretically by molecular docking studies. Using this technique, we can predict the best drug candidate in terms of protein inhibition, on a specific targeted protein. By molecular docking, we can predict binding energies, types of interactions and the amino acid profile residue of the protein that interacts with the drug molecule. In this study, we investigated the binding affinity of our studied molecules with HSA (human serum albumin). HSA, is the main transport protein in human organisms, were drugs bind and transported throughout the blood transportation. The 
interaction types between the chalcone molecules and their zinc complexes are given in Table 5. The energy function can be dissected into the following terms:

$E_{\text {tot }}=E_{\text {bind }}+E_{\text {pharma }}+E_{\text {ligpre }}(1)$

where $E_{b i n d}$ is the empirical binding energy used during the molecular docking; $E_{\text {pharma }}$ is the energy of binding-site pharmacophores; and $\mathrm{E}_{\text {ligpre }}$ is a penalty value if the ligand unsatisfied the ligand preferences. $E_{\text {pharma }}$ and $E_{\text {ligpre }}$ were used to improve the number of true positives by discriminating active compounds from hundreds of thousands of non-active compounds.

Table 5. Interaction types of the chalcone molecules and their zinc complexes.

\begin{tabular}{ccccc}
\hline Molecule & $\begin{array}{c}\text { Energy } \\
(\text { Kcal/mol) }\end{array}$ & $\begin{array}{c}\text { Van der } \\
\text { Waals } \\
(\mathrm{Kcal} / \mathrm{mol})\end{array}$ & $\begin{array}{c}\text { Hydrogen Bonding } \\
(\mathrm{Kcal} / \mathrm{mol})\end{array}$ & $\begin{array}{c}\text { Electrostatic Forces } \\
\text { (Kcal/mol) }\end{array}$ \\
\hline L1 & -78.63 & -65.08 & -13.55 & 0 \\
L2 & -76.66 & -59.16 & -17.50 & 0 \\
L3 & -84.53 & -65.31 & -19.22 & 0 \\
C1 & -82.64 & -62.09 & -20.55 & 0 \\
\hline C2 & -118.05 & -102.97 & -15.08 & 0 \\
\hline C3 & -94.29 & -73.61 & -20.67 & \\
\hline
\end{tabular}

It can be seen that $\mathbf{C}_{2}$, exhibit the highest binding affinity on the transport protein, followed by $\mathbf{C}_{3}$ and $\mathrm{L}_{3}$. The highest binding affinity exhibited by $\mathbf{C}_{2}$ is because of the $\mathrm{CH}_{3}-\mathrm{N}-\mathrm{CH}_{3}$ group which seems to interact better with the protein with van der Waals forces. The lowest binding affinity exhibited by $\mathrm{L}_{2}$, which means that in general, the complexed zinc (II) molecules are more active molecules with only exception the $\mathbf{C}_{1}$. In Table 6 . the amino acid residue of the protein that interact with the studied molecules can be seen.

Table 6. Interactions formed between the studied molecules with the amino acids of the transport protein. 


\begin{tabular}{cl}
\hline Molecule & \multicolumn{1}{c}{ Amino Acid Residue } \\
\hline L1 & Hydrophilic: GLN $33(-2.5)$, THR $83(-8.5)$ TYR $84(-2.5)$ \\
& Hydrophobic: LEU $31(-4.8)$, ARG $81(-4.1)$ GLU 82 (-9.6) THR $83(-5.4)$ \\
L2 & Hydrophilic: TYR $140(-4.1)$ GLU $141(-3.5)$ ARG $144(-9.9)$ \\
& Hydrophobic: PRO $35(-6.9)$ PHE $36(-5)$ GLU $37(-5)$ TYR $140(-9.3)$ \\
L3 & Hydrophilic: ASP $38(-2.5)$ HIS $39(-5.6)$ ARG $81(-3.4)$ THR $83(-6)$ \\
& Hydrophobic: LEU $31(-2.5)$ HIS $39(-5.6)$ ARG $81(-3.4)$ THR $83(-6)$ LEU 31 (-4.3) GLN 33 (-6.1) \\
& PRO 35 (-6.4) ASP $38(-4.4)$ VAL $77(-4.5)$ ARG $81(-7)$ TYR $84(-4)$ \\
C1 & Hydrophilic: ASP $38(-11)$ THR $83(-6.7)$ ARG $144(-2.8)$ \\
& Hydrophobic: GLN $33(-9.3)$ ASP $38(-5.8)$ ARG $81(6.3)$ LAU $112(-4.9)$ ARG $144(-5.1)$ \\
C2 & Hydrophilic: GLN $33(-3.2)$ PHE $36(-3.1)$ TYR $140(-5)$ ARG $144(-3.9)$ \\
& Hydrophobic: GLN $33(-7.4)$ PRO 35 (-9) PHE $36(-6.1)$ GLU $37(-7.7)$ LEU 112 (-4) TYR 140 (-13.6) \\
\hline \multirow{2}{*}{ C3 } & Hydrophilic: ASP $38(-10.7)$ ARG $81(-8.6)$ \\
& Hydrophobic: GLN $33(-11.8)$ PRO 35 (-7.7) ARG $81(-11.9)$ THR 83 (-12.8) \\
\hline
\end{tabular}

The best drug candidate of the six studied molecules with molecular docking $\left(\mathbf{C}_{2}\right)$, interacts both with hydrophilic and hydrophobic interactions. More specifically, $\mathbf{C}_{2}$ exhibits hydrogen bonds with GLN 33, PHE 36, TYR 140 and ARG 144 amino acids. Additionally, C $_{2}$, exhibits van der Waals interactions with GLN 33, PRO 35, PHE 36, GLU 37, LEU 112 and TYR 140 amino acids. Docking poses are depicted in Fig. 7.

\subsubsection{BSA Binding}

The structural changes of the protein and the complexation with the studied molecules has been done using UV-vis absorption measurements. The compounds interacted on the site I of the protein. We performed binding studies on the BSA protein because it has a similar shape with the HSA. The UV-vis absorption spectrums in Fig. 8 shows the effect of $L_{1}, L_{2}, L_{3}, C_{1}, C_{2}$ and $C_{3}$ molecules on the BSA spectrum. Strong absorption peaks at $250 \mathrm{~nm}$ and $350 \mathrm{~nm}$ can be seen for $L_{1}, L_{2}, L_{3}$ which are increased in intensities as the concentration of the molecules increases. The red shift observed at 250-255 nm indicates the complex formation of the protein with the ligands. When the $L_{1}, L_{2}$ and $L_{3}$ complexed with $\mathrm{Zn}$ (II), we observe in the spectrum of the protein only one strong absorption peak at 210-220 nm depending on the complex molecule. Again, the red shift of 1-5 nm corresponds to the ligation of the molecules in the protein structure. The Zn (II) ions are responsible for the loosening and unfolding of the protein backbone with an increase of the hydrophobicity of its environment, more drastically than the of $L_{1}, L_{2}, L_{3}$ molecules which $Z n$ is absent. Thus, the drastic change in the spectrum was happened by the complexed $\mathrm{C}_{1}, \mathrm{C}_{2}, \mathrm{C}_{3}$ molecules. Additionally, the results indicated that the interaction of the $\mathrm{Zn}$ (II) complexed chalcones with BSA molecule has caused some conformational changes in the microenvironment around chromophore of BSA, that is why we cannot observe any peak at the $300 \mathrm{~nm}$.

\section{Conclusions}


In this work, the synthesis of three chalcone derivatives and their corresponding Zn (II) molecules was presented and their structures evaluated spectroscopically and theoretically. Their spectroscopic and theoretical evaluation indicated that the Zn-chalcone molecules exhibited higher binding activity than their corresponding chalcone ligands. The binding activity was predicted with molecular docking studies and confirmed by spectroscopic BSA interactions of $L_{1}, L_{2}, L_{3}, C_{1}, C_{2}$ and $C_{3}$. From the highest to lowest activity the molecules are $C_{2}>C_{3}>L_{3}>C_{1}>L_{1}>L_{2}$. Chalcones are biological active molecules and their interactions with $\mathrm{Zn}$ metal ion increases their binding activity on transport proteins. Additionally, chalcones could be used as biological chelators to reduce the toxic zinc concentrations in biological systems.

\section{Declarations}

\section{CRediT authorship contribution statement}

Manos C. Vlasiou: Conceptualization, Methodology, Software, Experimentation, Writing - original draft, writing - review \& editing, validation.

\section{Declaration of competing interest}

The author declares that they have no known competing financial interests or personal relationships that could have appeared to influence the work reported in this paper.

\section{Acknowledgements}

The author wants to acknowledge the Pharmacy Programme of the University of Nicosia and Dr. Demetris Apostolides of the Department of Chemistry, of the University of Cyprus for the NMR experiments.

\section{References}

[1] Verma S, Srivastava AK, Pandey OP; A Review on Chalcones Synthesis and their Biological Activity;PharmaTutor; 2018; 6(2); 22-39; http://dx.doi.org/10.29161/PT.v6.i2.2018.22.

[2] M. Asad, M. Arshad, S. Khan, M. Oves, M. Khalid, A. Asiri et al., Cyclization of chalcones into Npropionyl pyrazolines for their single crystal X-ray, computational and antibacterial studies, Journal Of Molecular Structure. 1201 (2020) 127186. doi:10.1016/j.molstruc.2019.127186.

[3] Khor, S.W., Lee, Y.K., Abas, M.R.B. et al. Application of chalcone-based dithiocarbamate derivative incorporated sol-gel for the removal of $\mathrm{Hg}$ (II) ion from water. J Sol-Gel Sci Technol 82, 834-845 (2017). https://doi.org/10.1007/s10971-017-4362-7.

[4] R. Kamal, R. Kumar, V. Kumar, V. Bhardwaj, Synthetic Utilization of $a, \beta$-Chalcone Dibromide In Heterocyclic Chemistry and Stereoselective Debromination, Chemistryselect. 4 (2019) 11578-11603. 
[5] Xu Zhanga, K.P. Rakesha, S.N.A. Bukharia, Moku Balakrishnaa, H.M. Manukumarb, Hua-Li Qina, Multitargetable chalcone analogs to treat deadly Alzheimer's disease: Current view and upcoming advice, Bioorganic Chemistry 80 (2018) 86-93.

[6] Ayse Aktas Kamiloglu1, Hüseyin Karaca, Gonca Celik, Irfan Acar and Halit Kantekin, New chalconesubstituted metallophthalocyanines: Synthesis, characterization, and investigation of their properties, Journal of Chemical Research 1-10 (2020), https://journals.sagepub.com/doi/10.1177/1747519820902684.

[7] Mohamed Gabera, Hoda A. El-Ghamrya, Mohammed A. Mansourc, Pd(II) and Pt(II) chalcone complexes. Synthesis, spectral characterization, molecular modelling, biomolecular docking, antimicrobial and antitumor activities, Journal of Photochemistry and Photobiology A: Chemistry 354 (2018) 163-174.

[8] Gülpınar Sarkı, Halit Kantekin, Halise Yalazan, Nuran Kahriman, Zekeriya Biyiklioglu,

Vildan Serdaroglu, Synthesis, characterization and electrochemical studies of metal-free and metallophthalocyanines containing two different chalcone units substituted on peripherally positions, Journal of Molecular Structure 1196 (2019) 592e603.

[9] Chiara Sulpizio, Joscha Breibeck, Annette Rompel, Recent progress in synthesis and characterization of metal chalcone complexes and their potential as bioactive agents, Coordination Chemistry Reviews 374 (2018) 497-524.

[10] Mohammed Rayees Ahmad, V. Girija Sastry, Nasreen Bano, Syed Anwar, Synthesis of novel chalcone derivatives by conventional and microwave irradiation methods and their pharmacological activities, Arabian Journal of Chemistry (2016) 9, S931-S935.

[11] Mohammad Azam, Saud. I. Al-Resayes, Raghavaiah Pallepogu, Farha Firdaus, Mohammad Shakir, Mononuclear Bis(3-aminoquinoline)Zn(II) complexes: Synthesis and structural characterization, Journal of Saudi Chemical Society (2016) 20, 120-126.

[12] Artur Krezel, Wolfgang Maret, The biological inorganic chemistry of zinc ion, Archives of Biochemistry and Biophysics 611 (2016) 3e19.4

[13] Long Fan, Jing-can Qin, Chao-rui Li, Zheng-yin Yang, Two similar Schiff-base receptor based quinoline derivate: Highly selective fluorescent probe for Zn(II), Spectrochimica Acta Part A: Molecular and Biomolecular Spectroscopy (2018), https://doi.org/10.1016/ j.saa.2020.118347.

[14] Chenxiang Wang, Dawei Shi, Fangfang Zhang, Xuben Yu, Guanyang Lin, Ziye Zhou, Characterization of binding interaction between magnesium isoglycyrrhizinate and human serum albumin, Spectrochimica Acta Part A: Molecular and Biomolecular Spectroscopy 234 (2020) 118245. 
[15] ANKITA VARSHNEY, PRIYANKAR SEN, EJAZ AHMAD, MOHD. REHAN, NAIDU SUBBARAO, AND RIZWAN HASAN KHAN, Ligand Binding Strategies of Human Serum Albumin: How Can the Cargo be Utilized? CHIRALITY 22:77-87 (2010).

[16] Rachana Srivastava, Md. Sayem Alama, Spectroscopic studies of the aggregation behavior of Human Serum Albumin and cetyltrimethylammonium bromide, International Journal of Biological Macromolecules 158 (2020) 394-400.

[17] Tanveer A. Wani, Ahmed H. Bakheit, M. A. Abounassif and Seema Zargar, Study of Interactions of an Anticancer Drug Neratinib With Bovine Serum Albumin: Spectroscopic and Molecular Docking Approach, Frontiers in Chemistry, doi: 10.3389/fchem.2018.00047.

[18] Fang Shen, Ya-Xian Liu, Shu-Min Li, Chi-Kun Jiang, Bing-Feng Wang, Ya-Hong Xiong, Zong-Wan Mao and Xue-Yi Le, Synthesis, crystal structures, molecular docking and in vitro cytotoxicity studies of two new copper (II) complexes: special emphasis on their binding to HAS, NewJ.Chem., 2017, 41, 12429.

[19] Serpil Kaya, Sultan Erkan, Duran Karakaş, Computational investigation of molecular structures, spectroscopic properties and antitumor-antibacterial activities of some Schiff bases, Spectrochimica Acta Part A: Molecular and Biomolecular Spectroscopy 244 (2021) 118829.

[20] Prateek Tyagi, Sulekh Chandra, B.S. Saraswat b, Deepansh Sharma, Design, spectral characterization, DFT and biological studies of transition metal complexes of Schiff base derived from 2aminobenzamide, pyrrole and furan aldehyde, Spectrochimica Acta Part A: Molecular and Biomolecular Spectroscopy 143 (2015) 1-11.

[21] Gao-Jun Zhang, Shao-Yi Wu, Chen-Hao Liang, Yi-Mei Fan, Ying-Jie Luo, Jia-Xing Guo, Xiao-Yu Li, DFT calculations of the local structures and the EPR parameters for Rh2+ doped $A O(A=M g, C a)$ crystals, Chemical Physics 534 (2020) 110734.

[22] G. Kirishnamaline, J. Daisy Magdaline, T. Chithambarathanu, D. Aruldhas, A. Ronaldo Anuf, Theoretical investigation of structure, anticancer activity and molecular docking of thiourea derivatives, Journal of Molecular Structure 1225 (2021) 129118.

[23] Manish Kumar Tripathi, Piyoosh Sharma, Avanish Tripathi, Prabhash Nath Tripathi, Pavan Srivastava, Ankit Seth, Sushant Kumar Shrivastava, Computational exploration and experimental validation to identify a dual inhibitor of cholinesterase and amyloid-beta for the treatment of Alzheimer's disease, Journal of Computer-Aided Molecular Design.

[24] Jing Hu and Changhui Yan, A tool for calculating binding-site residues on proteins from PDB structures, BMC Structural Biology 2009, 9:52.

[25] Jingwei Zhou, Min Li, Nanhao Chen, Shenglong Wang, Hai-Bin Luo, Yingkai Zhang and Ruibo Wu, Computational Design of a Time-Dependent Histone Deacetylase 2 Selective Inhibitor, ACS Chem. Biol. 
[26] S. Syed Ali Fathima, M. Mohamed Sahul Meeran, E.R. Nagarajana, Synthesis of novel (E)-2((anthracen-9-ylmethylene) amino) pyridin-3-ol and its transition metal complexes: Multispectral characterization, biological evaluation and computational studies, Journal of Molecular Liquids 279 (2019) 177-189.

[27] R.N.S. Santiagoa, P.T.C. Freirea, A.M.R. Teixeirac, P.N. Bandeirae, H.S. Santose, T L.G. Lemosf, C.A.N. Ferrazc, FT-Raman and FT-IR spectra and DFT calculations of chalcone (2E)-1-(4-aminophenyl)-3-phenylprop-2-en-1-one, Vibrational Spectroscopy 97 (2018) 1-7.

[28] Shui Wang, Qiaoli He, Jidong Wang, Yixin Qu, Molecular structural, IR and NMR spectroscopic studies on the four isomers of thiotriazinone by DFT and HF calculations, Spectrochimica Acta Part A 87 (2012) $179-189$.

[29] Sudhir M. Hiremath, Seema S. Khemalapure, Chidanandayya S. Hiremath b, Anil S. Pati, Mahantesha Basanagouda, Quantum chemical computational and spectroscopic (IR, Raman, NMR, and UV) studies on the 5-(5-methoxy-benzofuran-3-ylmethyl)-3H-[1, 3, 4] oxadiazole-2-thione, Journal of Molecular Structure 1210 (2020) 128041.

[30] Parutagouda Shankaragouda Patil, Neelamma B. Gummagol, Anusha Ekbote, Qin AiWong, Ching Kheng Quah, Mohd Shkir, Shivaraj R. Maidur, S. Venugopal Rao, Journal of Molecular Structure 1219 (2020) 128523.

[31] Kereyagalahally Honneshappa Narasimhamurthy, Chandra, Toreshettahally Ramesh Swaroop, Swamy Jagadish and Kanchugarakoppal Subbegowda Rangappa, Synthesis of Piperidine Conjugated Dihydroquinazolin-4(1H)-ones and their Antiproliferative Activity, Molecular Docking Studies and DFT Calculations, Letters in Drug Design \& Discovery, 2020, 17, 85-93.

[32] Ajay Kumar, Kamlesh Kumari, Indra Bahadur, Prashant Singh, Temperature dependent DFT studies to understand the physiochemical interaction of lithium chloride cluster ions in presence of syringic acid, J. Chem. Thermodynamics 152 (2021) 106277.

[33] Bao-Li Wang, Dong-Qi Pan, Song-Bo Kou, Zhen-Yi Lin, Jie-Hua Shi, Exploring the binding interaction between bovine serum albumin and perindopril as well as influence of metal ions using multispectroscopic, molecular docking and DFT calculation, Chemical Physics 530 (2020) 110641.

[34] Sudhir M. Hiremath, A. Suvitha, Ninganagouda R. Patil, Chidanandayya S. Hiremath, Seema S. Khemalapure, Subrat K. Pattanayak, Veerabhadrayya S. Negalurmath, Kotresh Obelannavar, Molecular structure, vibrational spectra, NMR, UV, NBO, NLO, HOMO-LUMO and molecular docking of 2-(4, 6dimethyl-1- benzofuran-3-yl) acetic acid (2DBAA): Experimental and theoretical approach, Journal of Molecular Structure 1171 (2018) 362e374. 
[35] Nazia Siddiqui, Saleem Javed, Quantum computational, spectroscopic investigations on ampyra (4aminopyridine) by $\mathrm{df} t$ t/d-df $\mathrm{t}$ with different solvents and molecular docking studies, Journal of Molecular Structure 1224 (2021) 129021.

[36] Julian Tirado-Rives and William L. Jorgensen, Performance of B3LYP Density Functional Methods for a Large Set of Organic Molecules, J. Chem. Theory Comput. 2008, 4, 297-306.

\section{Figures}<smiles>CC(=O)c1cc(C)ccc1O</smiles>

1-(2-bydroxy-5-methylphenyl)ethanone Melecular Weight: 150.17

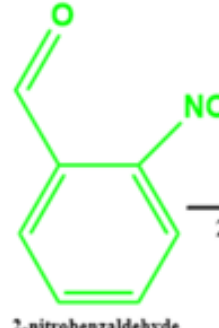

2-nitrebenzaldehyde Molecular Weight: is1.1<smiles>Cc1ccc(O)c(C(=O)/C=C/c2ccccc2[N+](=O)[O-])c1</smiles>

(E)-1-(2-hydroxy-5-methylpheny)-3-(2-nitrophenyD)prop-2-en-1-one

L1

L2<smiles>CC(=O)c1cc(C)ccc1O</smiles>

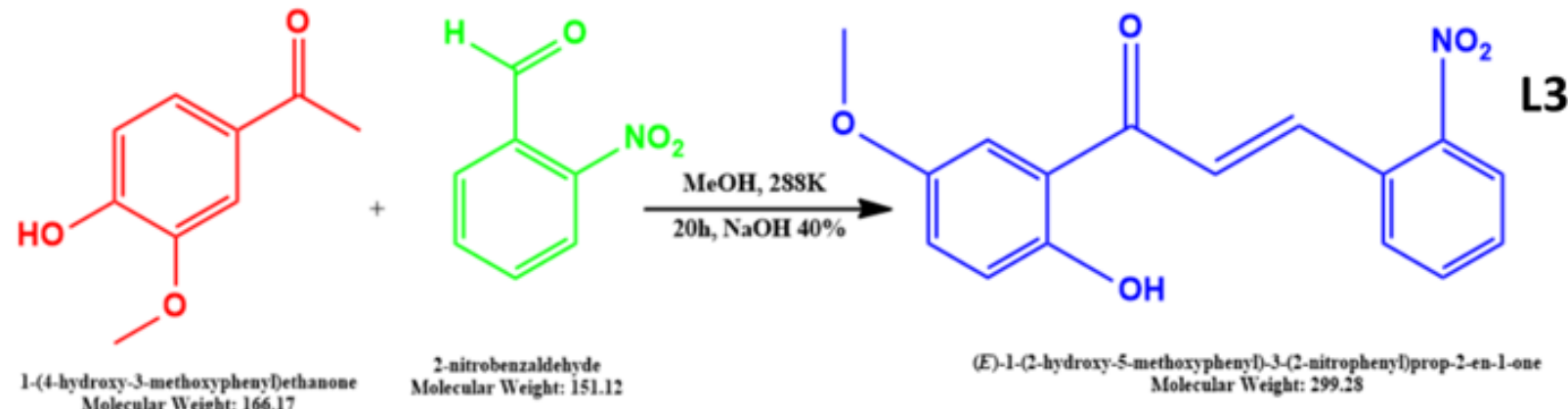

\section{Figure 1}

Synthetic routes of the three chalcone derivatives. 


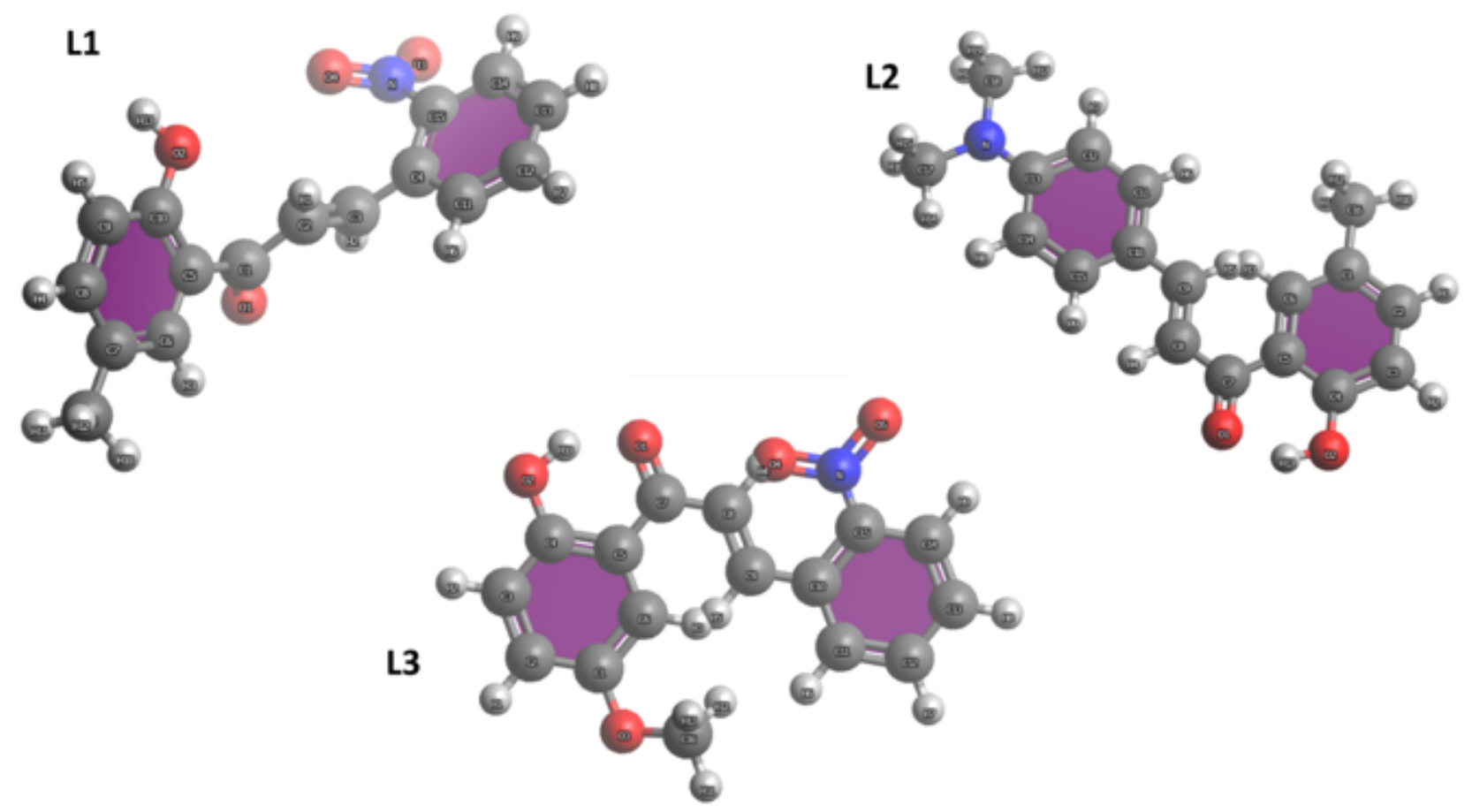

Figure 2

Optimized structures of the synthesized chalcones.
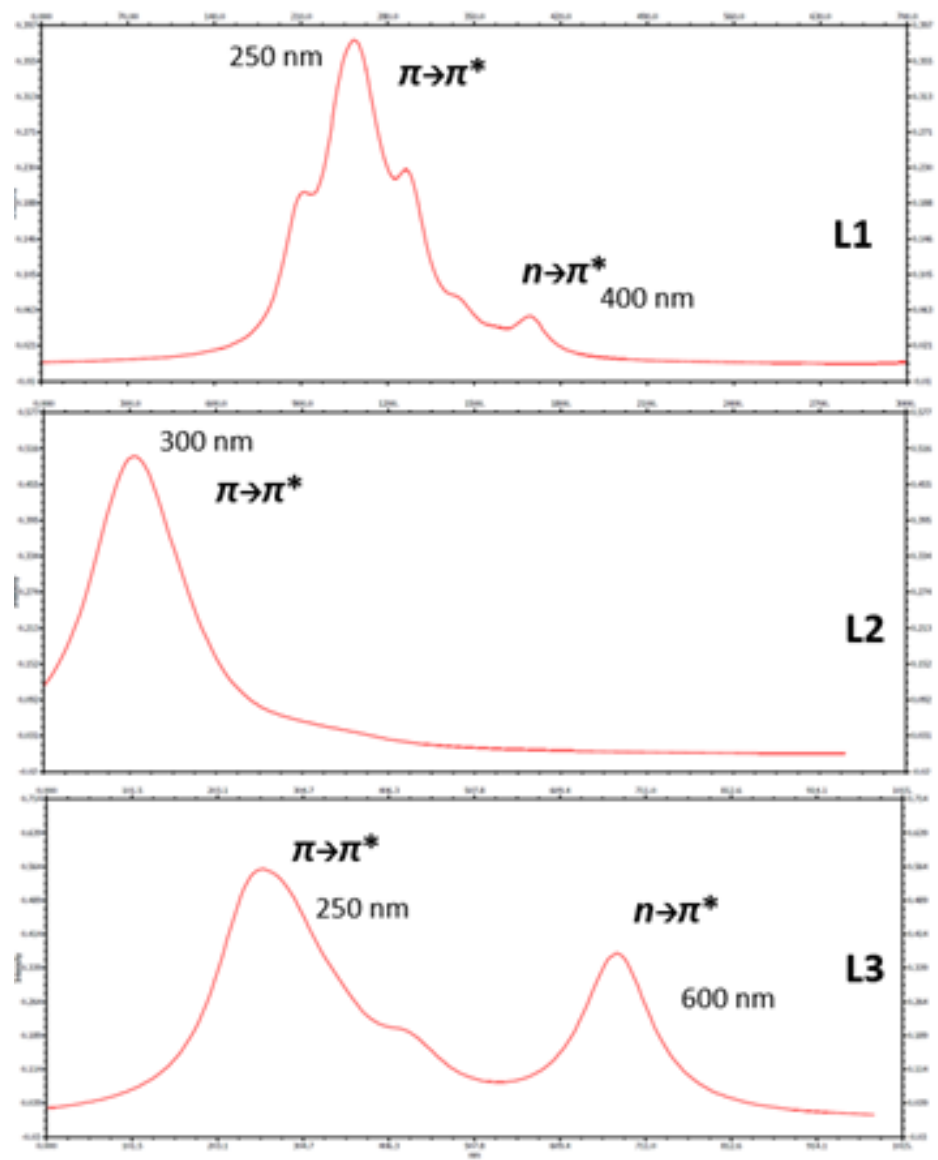

Figure 3 
Calculated UV-vis spectra of L1, L2 and L3 molecules.
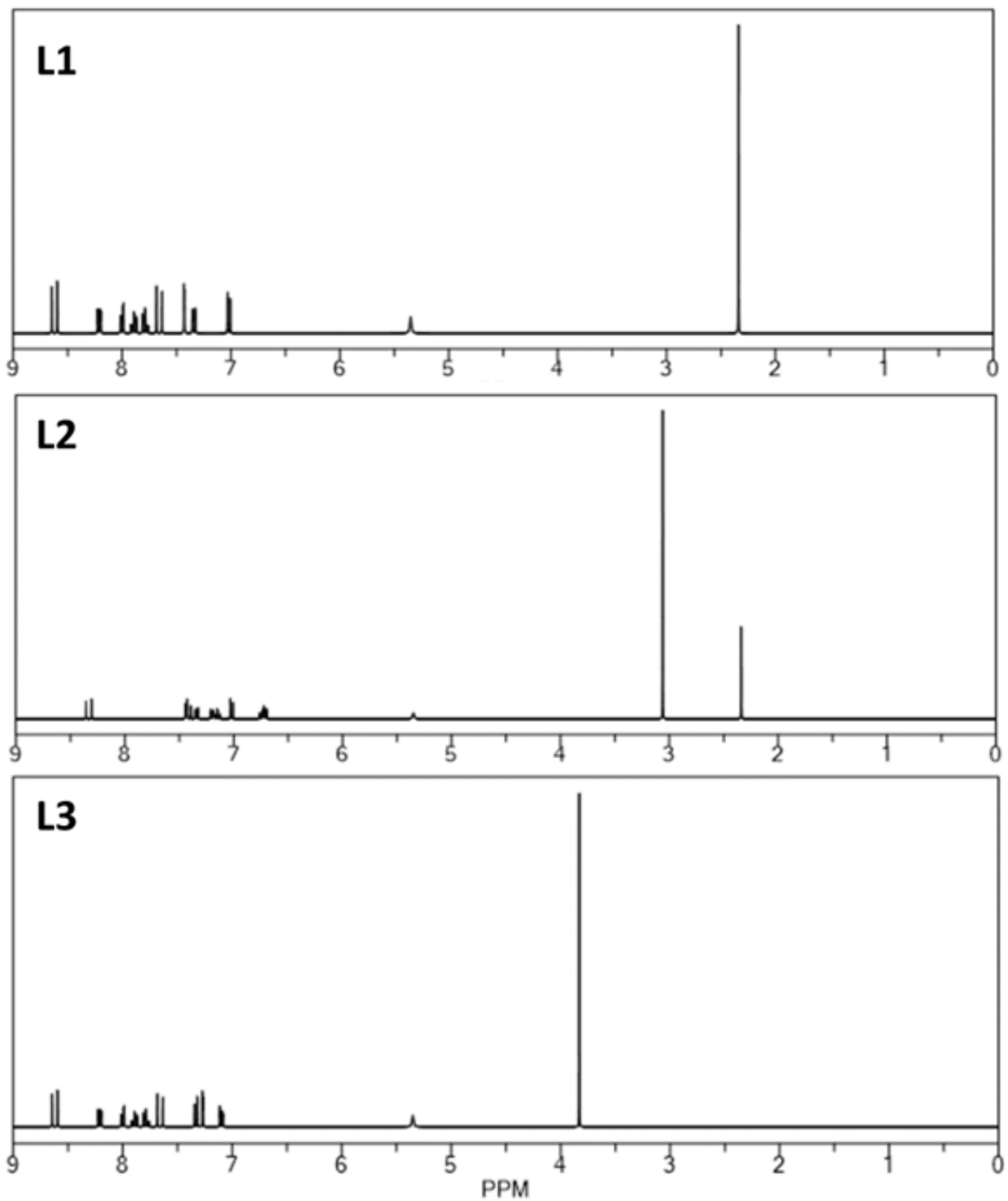

Figure 4

Calculated 1HNMR spectra of L1, L2 and L3 molecules. 


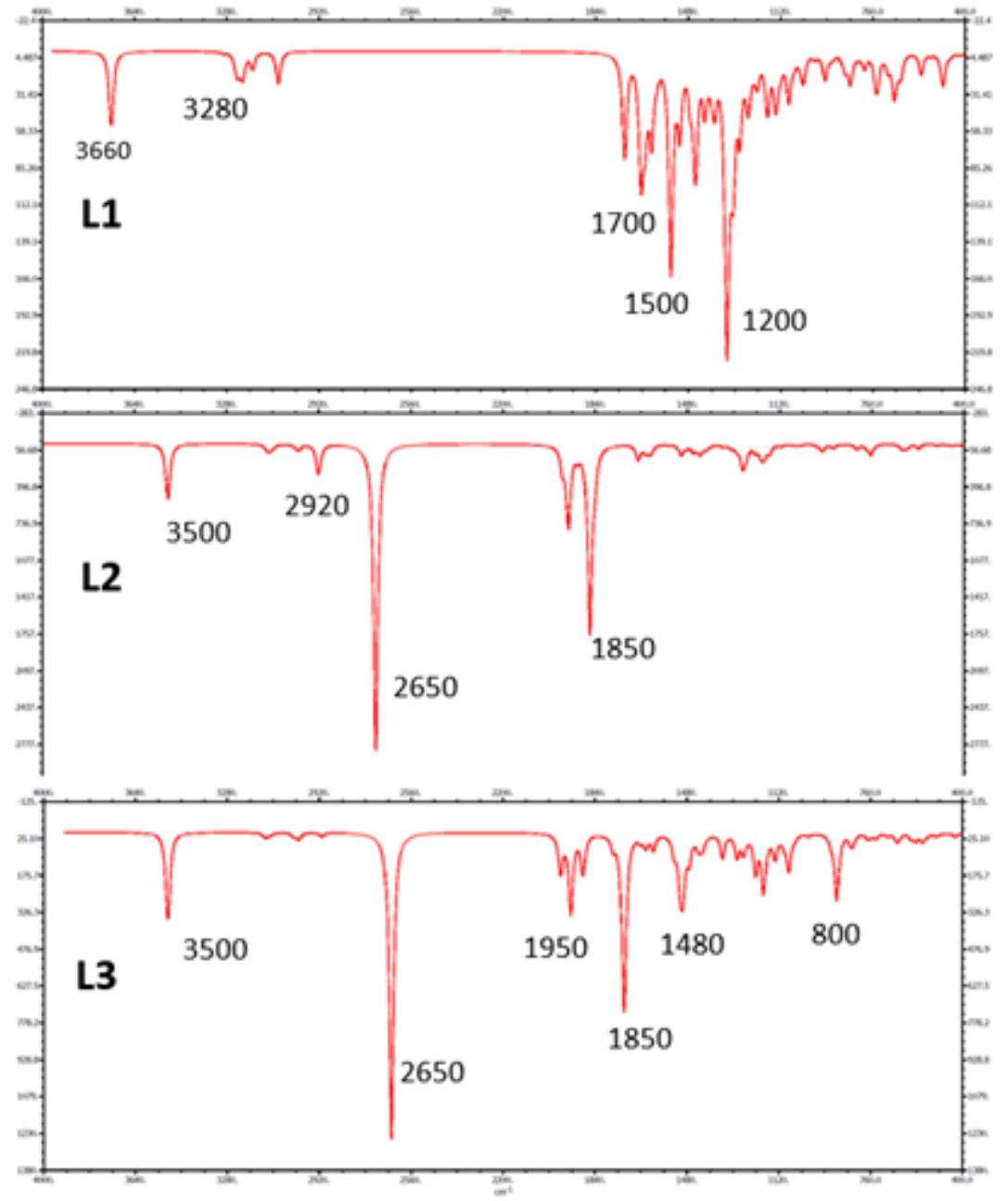

Figure 5

IR spectra of L1, L2 and L3 chalcone derivatives calculated in aqueous phase. 


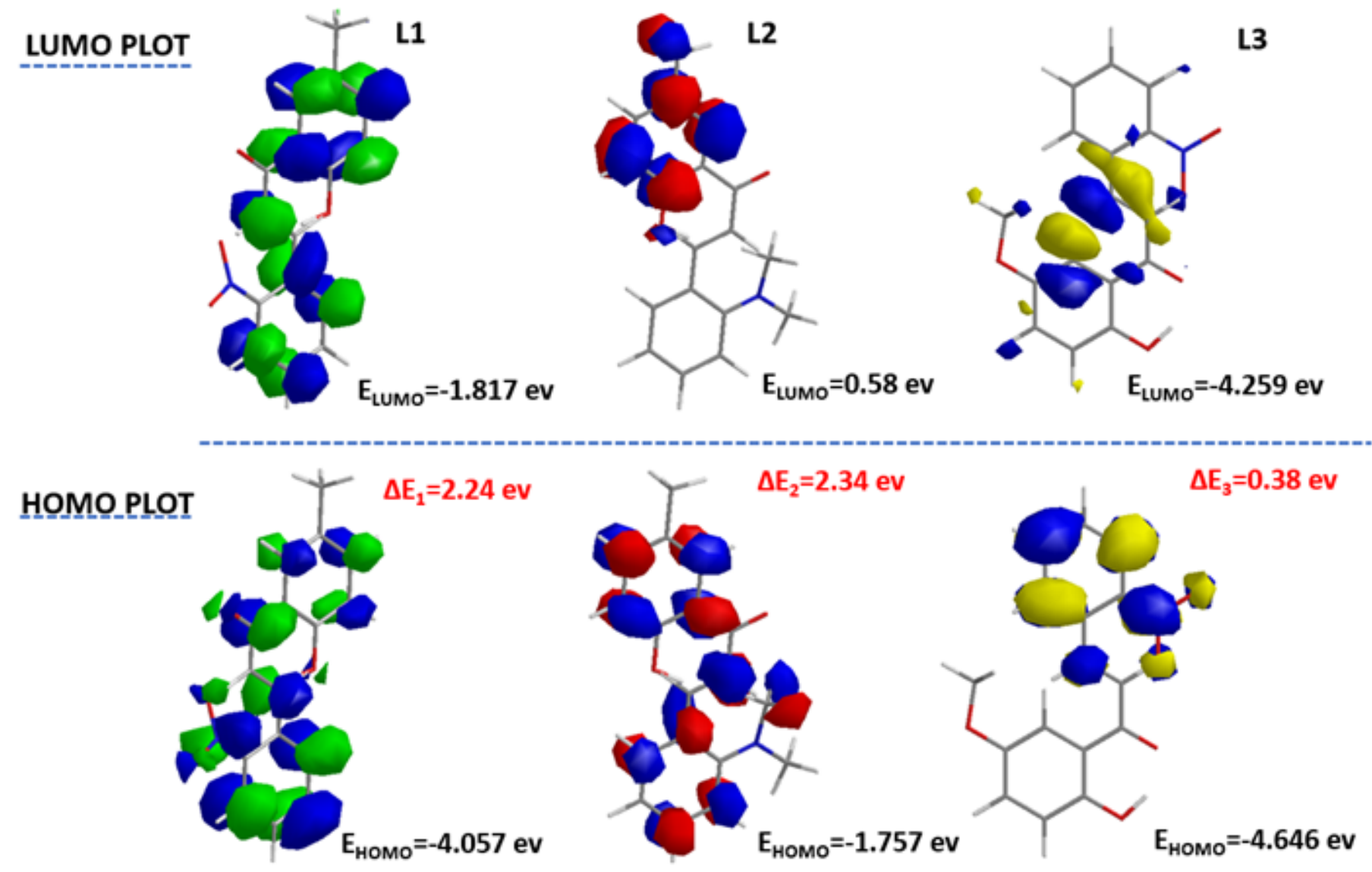

Figure 6

HOMO-LUMO orbitals of L1, L2 and L3 molecules. 


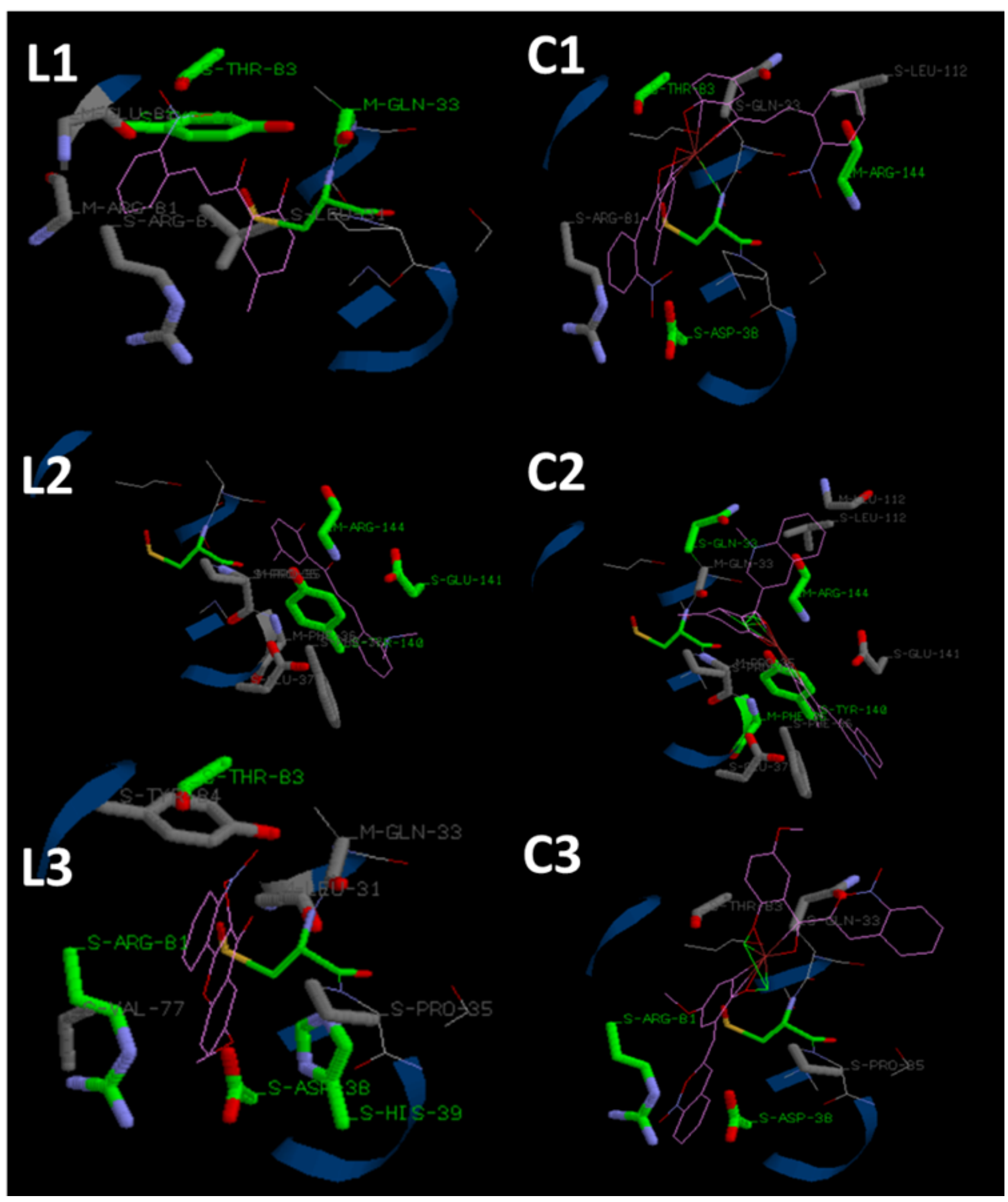

Figure 7

Interactions of the studied molecules in human serum albumin. 

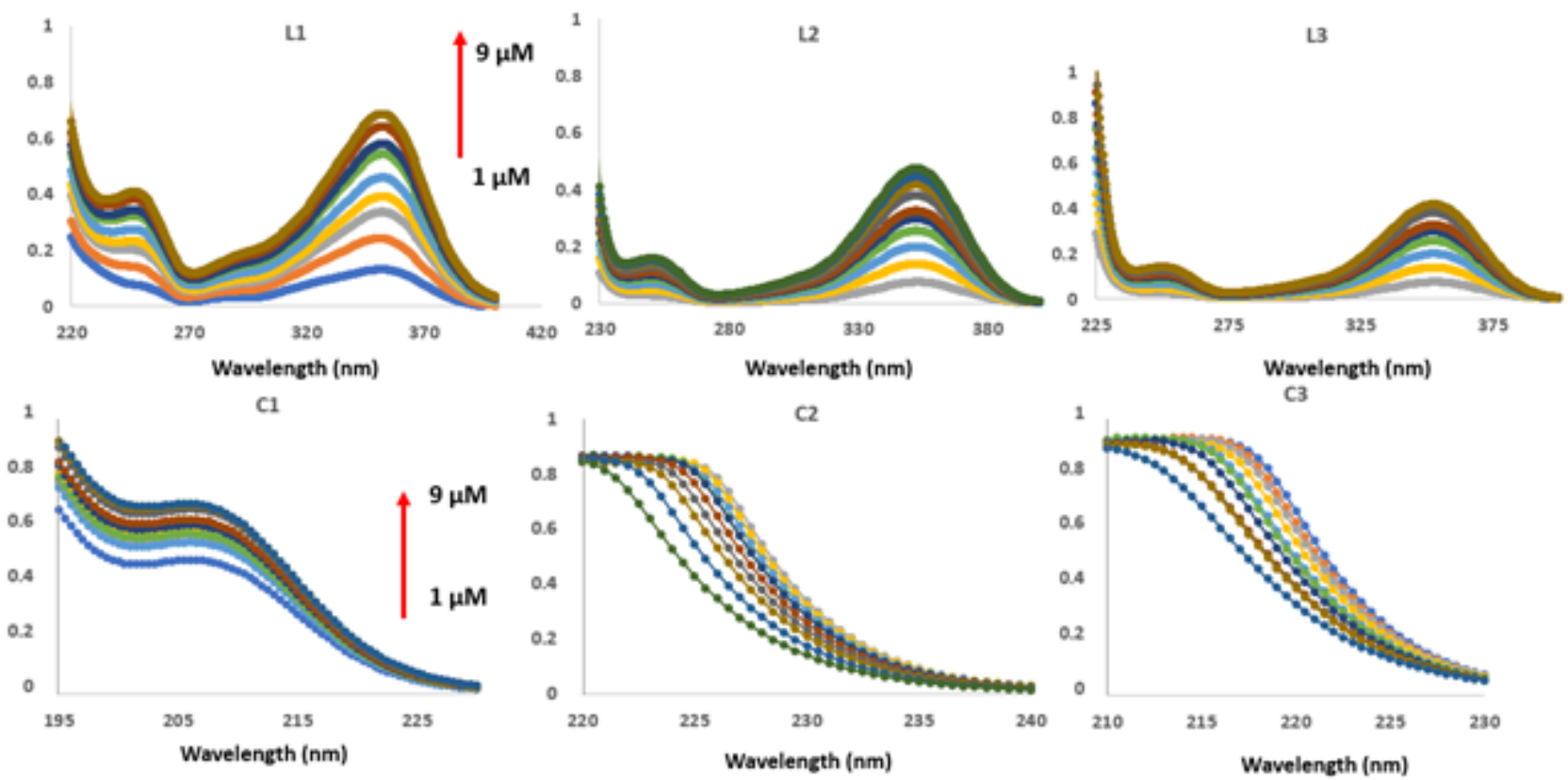

Figure 8

UV-vis spectra of $L 1, L 2, L 3, C 1, C 2, C 3(1-9 \mu M)$ interactions with BSA $(5 \mu M)$. 